\title{
Impact of socioeconomic deprivation on rate and cause of death in severe mental illness
}

\author{
Julie Langan Martin ${ }^{1 *}$, Gary McLean ${ }^{1}$, John Park², Daniel J Martin ${ }^{1}$, Moira Connolly ${ }^{3}$, Stewart W Mercer ${ }^{4}$ \\ and Daniel J Smith ${ }^{1}$
}

\begin{abstract}
Background: Socioeconomic status has important associations with disease-specific mortality in the general population. Although individuals with Severe Mental Illnesses (SMI) experience significant premature mortality, the relationship between socioeconomic status and mortality in this group remains under investigated. We aimed to assess the impact of socioeconomic status on rate and cause of death in individuals with SMI (schizophrenia and bipolar disorder) relative to the local (Glasgow) and wider (Scottish) populations.
\end{abstract}

Methods: Cause and age of death during 2006-2010 inclusive for individuals with schizophrenia or bipolar disorder registered on the Glasgow Psychosis Clinical Information System (PsyCIS) were obtained by linkage to the Scottish General Register Office (GRO). Rate and cause of death by socioeconomic status, measured by Scottish Index of Multiple Deprivation (SIMD), were compared to the Glasgow and Scottish populations.

Results: Death rates were higher in people with SMI across all socioeconomic quintiles compared to the Glasgow and Scottish populations, and persisted when suicide was excluded. Differences were largest in the most deprived quintile (794.6 per 10,000 population vs. 274.7 and 252.4 for Glasgow and Scotland respectively). Cause of death varied by socioeconomic status. For those living in the most deprived quintile, higher drug-related deaths occurred in those with SMI compared to local Glasgow and wider Scottish population rates $(12.3 \%$ vs. $5.9 \%, p=<0.001$ and $5.1 \% p=0.002$ respectively). A lower proportion of deaths due to cancer in those with SMI living in the most deprived quintile were also observed, relative to the local Glasgow and wider Scottish populations (12.3\% vs. 25.1\% $p=0.013$ and $26.3 \% p=<0.001$ ). The proportion of suicides was significantly higher in those with SMI living in the more affluent quintiles relative to Glasgow and Scotland (54.6\% vs. 5.8\%, $p=<0.001$ and $5.5 \%, p=<0.001$ ).

Conclusions: Excess mortality in those with SMI occurred across all socioeconomic quintiles compared to the Glasgow and Scottish populations but was most marked in the most deprived quintiles when suicide was excluded as a cause of death. Further work assessing the impact of socioeconomic status on specific causes of premature mortality in SMI is needed.

Keywords: Severe mental illness (SMI), Schizophrenia, Bipolar disorder, Mortality, Deprivation

\section{Background}

It is recognised that socioeconomic status has a significant impact on health and wellbeing and, with only a few exceptions, health outcomes are generally worse in deprived communities [1]. In Western societies, although there is evidence of equity in access to primary care services across different socioeconomic profiles, there is also

\footnotetext{
* Correspondence: julie.langan@glasgow.ac.uk

'Institute of Health and Wellbeing, University of Glasgow, Gartnavel Royal

Hospital, 1055 Great Western Road, Glasgow G12 OXH, UK

Full list of author information is available at the end of the article
}

evidence of inequalities in access to more specialist services $[2,3]$. In Scotland, which has had the highest mortality in Western Europe among working age (15-74 years) men and women since the late 1970s [4], premature mortality and inequalities in healthcare remain important $[5,6]$. In 2010 it was estimated that Scottish male mortality rates were around $20 \%$ higher and female working age mortality 30\% higher than the Western European mean. Although Scotland has been dubbed the "Sick Man of Europe", its biggest city Glasgow has even higher mortality rates, along with higher rates of deaths from suicide, drugs 
and alcohol and lower life expectancy than the rest of Scotland [7]. While it is known that the impact of deprivation on health and mortality is large, the differences in life expectancy in Scotland compared to the rest of Europe (and in Glasgow compared to the rest of Scotland) cannot be fully explained by differences in its deprivation profile alone. These differences which are unexplained by deprivation have been termed the "Scottish" and "Glasgow" Effects.

For individuals with SMI, the increase in standardised mortality rates (SMRs) compared to the general population is substantial [8-11]. On average, men with schizophrenia die 20 years earlier and women die 15 years earlier than the general population $[12,13]$. For bipolar disorder, life expectancy is estimated to be reduced by approximately 10 years in men and 11 years in women [11]. Furthermore, there is recent evidence from the UK [12], US [13] and Western Australia [14] to suggest that this mortality gap may be getting worse. Although it is recognised that individuals with SMI have more physical health problems than the general population $[15,16]$, there is also evidence of inequalities for both access to and the quality of a range of physical healthcare services [17-21]. In combination with the inequality in access to treatment, it is recognised that SMI individuals tend to experience a greater downward trend in socioeconomic status over time compared to the general population [22]. Despite the important and complex interaction between socioeconomic status and mortality, little work has specifically focused on this relationship for individuals with SMI. Here we describe and compare rates and causes of death for individuals with schizophrenia and bipolar disorder who were registered on the Glasgow Psychosis Clinical Information System (PsyCIS) according to socioeconomic quintile, relative to the local Glasgow population and the wider Scottish population. We seek to determine if as is seen in the general population, increasing deprivation is associated with increased mortality rates and we also examined whether or not the "Glasgow" Effect was present in our cohort of individuals with SMI.

\section{General methods}

\section{Construction and content of the database}

The Glasgow Psychosis Clinical Information System (PsyCIS) is a database of all individuals with psychotic illness who have been in contact with secondary care psychiatric services in Glasgow, Scotland, covering a population of approximately 1 million people. Data were initially collected retrospectively by two research nurses. From August 2005 onwards new cases have been added prospectively to the database using existing patient information management systems. All patients have detailed socio-demographic information including International
Statistical Classification of Diseases and Related Health Problems (ICD-10) diagnosis, unique Community Health Index (CHI) number, postcode, educational attainment, family history of psychosis, psychiatric admissions data, use of the Mental Health Act, current and previous medications, adverse drug effects, psychosocial interventions received and psychiatric comorbidities. All patients provide annual follow up information and there is a reciprocal relationship between local clinicians and the PsyCIS team which facilitates the return to consultants of clinically relevant information at an individual caseload level.

The dataset is regularly added to and updated and currently holds information on over 7,200 patients with a diagnosis of psychotic disorder, including: schizophrenia $(\mathrm{n}=4,787)$; bipolar disorder $(\mathrm{n}=1,784)$; organic psychosis $(n=67)$; psychotic depression $(n=452)$; and substanceinduced psychosis $(n=160)$ [23]. There is a process of annual review to check the accuracy of information, such as diagnosis, postcode and current medication and the database has undergone internal validity checking to determine the diagnostic accuracy of individual ICD10 diagnoses.

\section{Sample}

All individuals with schizophrenia or bipolar affective disorder aged between 18 and 65 who had died between 2006 and 2010 and lived within the Greater Glasgow area covered by PsyCIS were identified $(n=230)$. Date and cause of death were obtained by linkage to the Scottish Morbidity Records (SMR) held by the Information Services Division of NHS Scotland [24] using patient $\mathrm{CHI}$ number. The ICD 10 code was used to group cause of deaths, into 9 categories using information from the Scottish Government website [25]: 1) cardiovascular disease, 2) cerebrovascular disease, 3) respiratory diseases, 4) cancer, 5) alcohol related deaths, 6) mental and behavioural disorder due to drugs, 7) accidental, 8) suicide as defined by the Scottish suicide information database [26] (which includes deaths of undetermined origin) and 9) other (Table 1). Ethical Approval for this project was obtained from the NHS Greater Glasgow and Clyde Caldicott Guardian.

\section{Methods}

We used the Scottish Index of Multiple Deprivation (SIMD) score as a measure of social deprivation. The SIMD identifies small areas of multiple deprivation (datazones) across Scotland by combining 38 indicators across 7 domains which are weighted. The domains include: current income, employment, health, education, geographic access to services, crime, and housing and are weighted based on evidence from Oxford University's Social Disadvantage Research Centre [27]. Each domain contains information gathered from multiple sources, 
Table 1 ICD 10 Codes for Cause of death

\begin{tabular}{|c|c|}
\hline Main categories of cause of death & ICD 10 Codes \\
\hline 1) Cardiovascular disease & I20-125- including acute MI I219 \& atherosclerotic heart disease I251 \& I259 \\
\hline 2) Cerebrovascular disease & $\begin{array}{l}\text { 160-169- including subarachnoid haemorrhage 1600, 1609, brain stem } \\
\text { intra cerebral haemorrhage 1613, subdural haemorrhage 1620, other } \\
\text { unspecified stroke } 164 \text { \& cerebral infarction 1639, } 1693 \& 1679\end{array}$ \\
\hline 3) Respiratory diseases & $\begin{array}{l}\text { J00-J99- including, COPD J441 \& J449, pneumonia J189, J22 \& } \\
\text { J690, emphysema J439, asthma J459 \& bronchiectasis J459 }\end{array}$ \\
\hline 4) Cancer & $\begin{array}{l}\text { C00-C97- including oral C069 \& C329, Gl tract C159, } \\
\text { C169,19 \& C20, lung C349, cervix C539, brain C719, skin C446, } \\
\text { bladder C679 \& lymphoma C819 \& C851 }\end{array}$ \\
\hline 5) Alcohol related deaths & $\begin{array}{l}\text { including mental and behavioural disorder due to use of alcohol F10, } \\
\text { degeneration of nervous system due to alcohol G31.2, alcoholic polyneuropathy } \\
\text { G62.1, alcoholic cardiomyopathy 142.6, alcoholic gastritis K29.2, alcoholic liver disease } \\
\text { K70, chronic hepatitis, not elsewhere classified K73, fibrosis and cirrhosis of liver K74 } \\
\text { (excluding K74.3-K74.5 - biliary cirrhosis), alcohol induced chronic pancreatitis K86.0, } \\
\text { accidental poisoning by, and exposure to, alcohol X45 intentional self-poisoning by, } \\
\text { and exposure to, alcohol, X65, poisoning by, and exposure to, alcohol; undetermined } \\
\text { intent Y15 }\end{array}$ \\
\hline 6) Mental and behavioural disorder due to drugs & F11-F16 \& F18-F19 \\
\hline 7) Accidental & $\begin{array}{l}\text { Including transport accidents V01-V99, falls W00-W19, death due to fire X00, } \\
\text { accidental poisoning } X 40-X 49 \text {, assault X04 \& X59-Y09 and other accidents Y85 \& Y86 }\end{array}$ \\
\hline 8) Suicide & $\begin{array}{l}\text { As defined by the Scottish suicide information database }{ }^{17} \text { (X60-X84 \& Y87.0 and deaths } \\
\text { of undetermined origin } Y 10-Y 34) \text { including- intentional self-poisoning X61 \& X62, } \\
\text { intentional hanging X70, intentional drowning X71, intentional jump from height X80, } \\
\text { intentional jump before moving object X81, intentional death by fire X76, poisoning of } \\
\text { undetermined intent } Y 11 \text { \& } Y 12 \text {, fall or jump from height of undetermined intent } \\
Y 30 \text { \& undetermined cause of death } Y 34\end{array}$ \\
\hline 9) Other & $\begin{array}{l}\text { Including all other codes not included in above 1-8. A00-B99, E00-E99, G00-G30, } \\
\text { G32-G61, G62-G99, H00-H95, I00-I19, I26-141, I43-159, I70-199, K00-K28, K30-KK69, } \\
\text { K70-K85, K87-K93, L00-L99. M00-M99, N00-N99, O00-O99, Q00-Q99, R00-R99, } \\
\text { in particular left ventricular failure I501, hypertensive disease I119, aortic aneurysm } \\
\text { I711 \& I713, peripheral vascular disease E145, ischaemic gut K550, cardiomegaly I517, } \\
\text { cardiomyopathy 1426 \& 1429, valvular disease I080, sarcoidosis D869, PE I269, obesity } \\
\text { E668 \& E669, unspecified cardiac arrest 1469, unspecified diabetes E149, diabetic coma } \\
\text { E140, diabetic ketoacidosis E141 and diabetes with renal complications E122, UTI N390, } \\
\text { septicaemia A419, hypo-osmolality E871, phlebitis I803, GI haemorrhage K922, gastrointestinal } \\
\text { ulcer K221, K254 \& K264, appendicitis K37, intestinal obstruction K566 and renal failure N19 }\end{array}$ \\
\hline
\end{tabular}

for example the health domain contains information regarding: hospital episodes related to alcohol use, hospital episodes related to drug use, a measure of mortality (the comparative mortality factor (CMF)), a measure of morbidity (comparative illness factor), emergency admission to hospital, population proportion prescribed drugs for anxiety, depression or psychosis and proportion of singleton births of low birth weight $(<2,500 \mathrm{~g})$. Each individual was allocated to a datazone and subsequent SIMD category based on their postcode $(1=$ most affluent and $5=$ most deprived). There are 6,505 datazones covering Scotland and the SIMD score provides a relative measure of deprivation.

\section{Analyses}

Rate of death/10,000 population per 5 years by SIMD quintile for the total deceased SMI population (schizophrenia and bipolar disorder combined) was calculated and compared with rate of death in the local Glasgow and wider Scottish Population over the total study time period, using mortality data available from the General Register
Office for Scotland. The "Glasgow" Effect was determined by comparison of rate of death between groups. Both allcause mortality rate and mortality rate excluding suicide in the SMI population were calculated. The rationale being that as suicide is a major contributor to premature death in SMI it may in itself be influenced by socioeconomic status. Cause of death by SIMD quintile for the total deceased SMI population (schizophrenia and bipolar disorder combined) was calculated and compared with cause of death in the local Glasgow and wider Scottish Population over the total study time period, using mortality data. Rates and patterns in cause of death by deprivation quintile were compared in those with SMI to the local Glasgow and wider Scottish populations using Chi squared tests. All statistical tests were performed using STATA version 12.

\section{Results}

Patterns of mortality in those with severe mental illness The primary cause of death in those with SMI differed from that seen in the local Glasgow and wider Scottish 
populations (Table 2). When age at death was considered, a higher proportion of those with SMI who had died were aged 25-34 and 35-44 compared to those who had died in Scotland $(7.8 \%$ vs. $5.8 \%, \mathrm{p}=<0.001$ and $16.5 \%$ vs. $12.5 \%, \mathrm{p}=<0.001$ ) (Table 2 ). The proportion of deaths by age group in those with SMI was more similar to the pattern observed locally in Glasgow (Table 2). The proportion of men that died in each group was similar: $67.8 \%$ of deaths in those with SMI were in men, $64.5 \%$ of deaths in Glasgow were in men $(p=0.298)$ and $61.9 \%$ of deaths in Scotland were in men $(\mathrm{p}=0.063)$ (Table 2).

Cause of death differed between the three groups: for example, death due to cancer occurred less frequently in those with SMI compared to the local Glasgow and wider Scottish populations $(14.3 \%$ vs. $27.3 \%, \mathrm{p}=<0.001$ and $33.2 \%, \mathrm{p}=<0.001$ ) (Table 2). Alcohol related deaths were also lower (6.5\% (SMI) vs. $12.8 \%$ (Glasgow), $\mathrm{p}=$ 0.005 and 9.7\% (Scotland), $\mathrm{p}=0.099$ ) (Table 2). However, the proportion of suicides was higher in those with SMI compared to that seen in the local Glasgow and wider
Scottish populations $(14.8 \%$ vs. $7.0 \%, \mathrm{p}=<0.001$ and $6.5 \%, \mathrm{p}=<0.001)$, as were drug related deaths $(7.8 \%$ vs. $5.1 \%, \mathrm{p}=0.065$ and $3.2 \%, \mathrm{p}=<0.001$ ) (Table 2). The proportion of deaths due to cardiovascular disease were similar across the three groups $(14.8 \%$ in those with SMI, $13.2 \%$ in those living in Glasgow $(\mathrm{p}=0.546)$ and $13.7 \%$ in those living in Scotland $(\mathrm{p}=0.626)$.

\section{Patterns of mortality by socioeconomic status}

The rate of death per 10,000 population per 5 years for SMI compared to the local Glasgow and wider Scottish populations was higher across all socioeconomic quintiles and persisted even when suicide was excluded as a cause of death (Figure 1). For example, in the most deprived cohort, the rate of death (excluding suicide) in those with SMI was 697.2 per 10,000 population compared to a rate of 252.4 per 10,000 population for Scotland and 274.7 per 10,000 population for Glasgow. When suicide was excluded as a cause of death, the increase in mortality associated with deprivation was larger in those with SMI compared to those living in Glasgow and Scotland.

Table 2 Rate and cause of death and socioeconomic profile of the deceased SMI group compared to Glasgow City and Scottish Populations (2006-2010)

\begin{tabular}{|c|c|c|c|c|c|}
\hline & $\begin{array}{l}\text { Combined SMI } \\
\text { group }(n=230)\end{array}$ & Glasgow City $(n=8,094)$ & $P^{1}$ & Scotland $(n=54,590)$ & $P^{2}$ \\
\hline \multicolumn{6}{|l|}{ Cause of death $(n, \%)$} \\
\hline Cerebrovascular disease & $8(3.5 \%)$ & $304(3.8 \%)$ & $p=0.833$ & $2186(4.0 \%)$ & $p=0.685$ \\
\hline Cardiovascular disease & $34(14.8 \%$ & $1069(13.2 \%)$ & $p=0.546$ & $7465(13.7 \%)$ & $p=0.626$ \\
\hline Cancer & $33(14.3 \%)$ & $2211(27.3 \%)$ & $p<0.001$ & $18129(33.2 \%)$ & $p<0.001$ \\
\hline Respiratory disease & $24(10.4 \%)$ & $606(7.5 \%)$ & $p=0.096$ & $3451(6.3 \%)$ & $p=0.001$ \\
\hline Alcohol Related & $15(6.5 \%)$ & $1032(12.8 \%)$ & $p=0.005$ & $5319(9.7 \%)$ & $p=0.099$ \\
\hline Accidental deaths & $11(4.8 \%)$ & $400(4.9 \%)$ & $p=0.912$ & $2882(5.3 \%)$ & $p=0.734$ \\
\hline Suicide & $34(14.8 \%)$ & $568(7.0 \%)$ & $p<0.001$ & $3533(6.5 \%)$ & $p<0.001$ \\
\hline Mental \& behavioural disorder due to drugs & $18(7.8 \%)$ & $412(5.1 \%)$ & $p=0.065$ & $1756(3.2 \%)$ & $p<0.001$ \\
\hline Other & $53(23.0 \%)$ & $1492(18.4 \%)$ & $p=0.076$ & $9869(18.1 \%)$ & $p=0.05$ \\
\hline Male $(n, \%)$ & $156(67.8 \%)$ & $5218(64.5 \%)$ & $p=0.298$ & $33772(61.9 \%)$ & $p=0.063$ \\
\hline \multicolumn{6}{|l|}{ Deaths/age group (n, \%) } \\
\hline $16-24$ & $3(1.3)$ & $238(2.9)$ & $p=0.144$ & $1902(3.5)$ & $p=0.07$ \\
\hline $25-34$ & $18(7.8)$ & $559(6.9)$ & $p=0.588$ & $3186(5.8)$ & $p<0.001$ \\
\hline $35-44$ & $38(16.5)$ & $1250(15.4)$ & $p=0.656$ & $6841(12.5)$ & $p<0.001$ \\
\hline $45-54$ & $72(31.3)$ & $2171(26.8)$ & $p=0.131$ & $13841(25.4)$ & $p=0.039$ \\
\hline $55-64$ & $99(43.0)$ & $3876(47.9)$ & $p=0.147$ & $28820(52.8)$ & $p=0.003$ \\
\hline \multicolumn{6}{|l|}{ Deaths/Socioeconomic Status ( $\mathrm{n}, \%$ ) } \\
\hline 1-Most affluent & $11(4.8 \%)$ & $257(3.2 \%)$ & $p=0.173$ & $5974(10.9 \%)$ & $p=0.003$ \\
\hline $2-$ & $15(6.5 \%)$ & $450(5.6 \%)$ & $p=0.531$ & $8244(15.1 \%)$ & $p=0.0003$ \\
\hline $3-$ & $34(14.8 \%)$ & 732 (9.0\%) & $p=0.003$ & 10338 (18.9\%) & $p=0.108$ \\
\hline 4- & $64(27.8 \%)$ & 1286 (15.9\%) & $p<0.001$ & 12643 (23.2\%) & $p=0.09$ \\
\hline 5-Most deprived & $106(46.1 \%)$ & 5369 (66.3\%) & $p<0.001$ & 17391 (31.9\%) & $p<0.001$ \\
\hline
\end{tabular}

$\mathrm{P}^{1}$ Chi squared combined SMI group vs. Glasgow City.

$\mathrm{P}^{2}$ Chi squared combined SMI group vs. Scotland. 


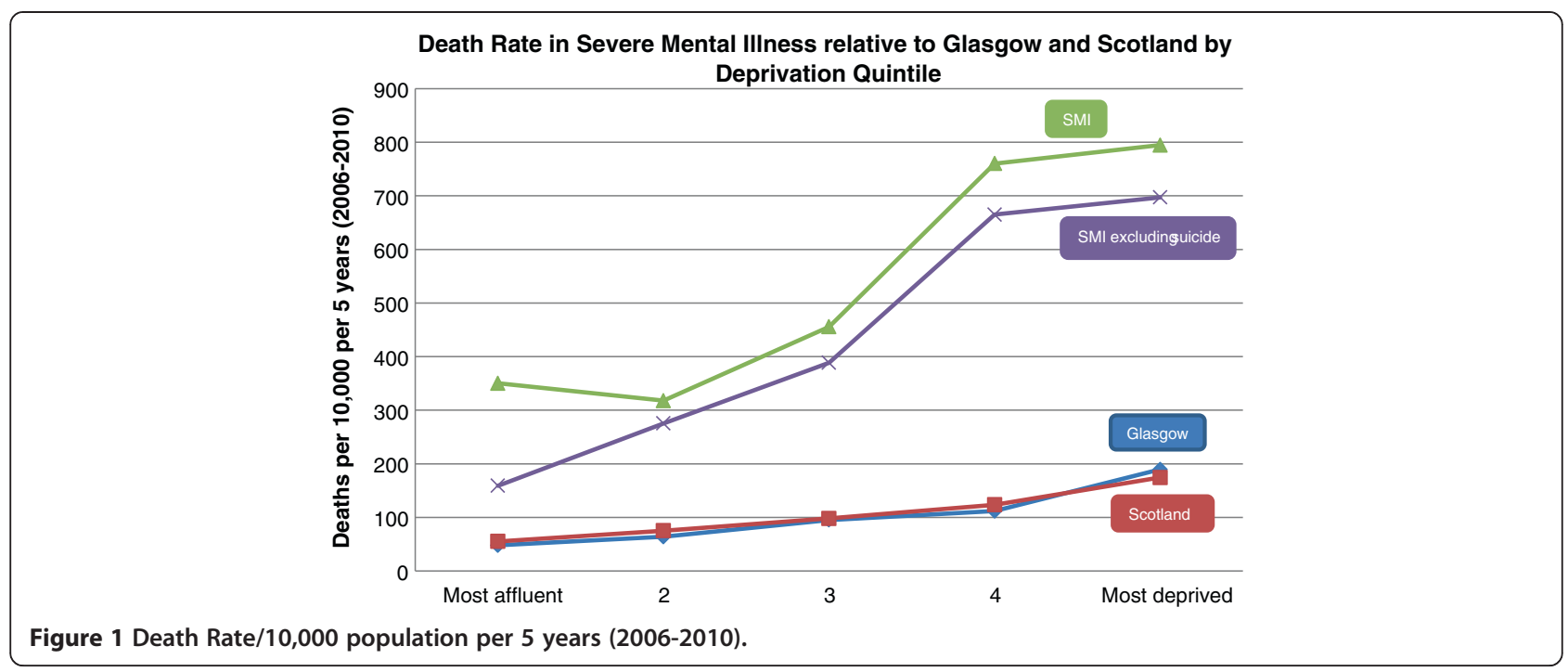

When the primary cause of death for individuals with SMI was reported in more detail by deprivation quintile, and compared to the local Glasgow and wider Scottish populations, a number of differences were identified. For those living in the most deprived cohort, higher drugrelated deaths occurred in those with SMI compared to the local Glasgow and wider Scottish population rates $(12.3 \%$ vs. $5.9 \%, \mathrm{p}=<0.001$ and $5.1 \% \mathrm{p}=0.002$ respectively) (Table 3). A lower proportion of deaths due to cancer in those with SMI living in the most deprived quintile were also observed, relative to the local Glasgow and wider Scottish populations $(12.3 \%$ vs. $25.1 \% \mathrm{p}=$ 0.013 and $26.3 \% \mathrm{p}=<0.001$ ) (Table 3).

The proportion of suicide was significantly higher in those with SMI living in the more affluent quintiles relative to the local Glasgow and wider Scottish populations (54.6\% vs. $5.8 \%, \mathrm{p}=<0.001$ and $5.5 \%, \mathrm{p}=<0.001$ ) (Table 3 ). Similarly, an increase in proportion of suicide was observed for those with SMI living in the most deprived quintile compared to the local Glasgow and wider Scottish population $(12.3 \%$ vs. $6.9 \%, \mathrm{p}=0.05$ and $6.9 \%, \mathrm{p}=0.05)$ (Table 3).

\section{Discussion}

Our cohort of individuals with SMI had higher mortality rates compared to both the local Glasgow and wider Scottish populations, consistent with several other studies which have used similar secondary care mental health registers [28-30]. The proportion of deaths by age group was similar to that seen in the local Glasgow population, but differed from that of the wider Scottish population, with a larger proportion of deaths occurring in those aged 25-44 years with SMI. As occurs in the general population, increasing socioeconomic deprivation appeared to be associated with an increased overall rate of death in those with SMI.

\section{Differences in the rate, age and cause of death}

We found that although individuals with SMI died younger than the Scottish population, the age at death was similar to the local Glasgow population. This is potentially in keeping with the "Glasgow" Effect whereby average age at death in Glasgow is lower than the Scottish average. However despite this, differences in cause and rate of death between the SMI and Glasgow groups were apparent. In particular, and perhaps surprisingly, deaths due to cancer and alcohol were lower in the SMI group compared to the Glasgow group. To date, the literature surrounding cancer deaths in individuals with SMI has been mixed, with some studies reporting elevated rates [31], while others report lower rates of cancer deaths [32]. A recent meta-analysis of incidence of cancer [33], reported that pooled overall rates of cancer incidence were not significantly increased in individuals with schizophrenia compared to controls (Standardised Incidence Rate (SIR) 1.05, 95\% CI 0.95-1.15) and although incidence of lung cancer was increased, when adjusted for smoking there was no difference in incidence rates. Indeed it also reported that the incidence of several cancers unrelated to smoking was reduced in individuals with schizophrenia. These mixed findings in cancer rates may in part, help explain the unclear evidence for cancer mortality rates in individuals with SMI and highlight the need for further longitudinal research in this area.

Our finding of lower rates of death due to alcohol are perhaps surprising given the high rates of alcohol dependence reported in individuals with SMI $[34,35]$. This may in part be explained by the elevated population levels of alcohol related deaths in Scotland compared to other countries. In 2011 the Scottish male alcohol mortality rate was $28.4 / 100,000$ compared to the UK average of 17.2/100,000 while in women the Scottish alcohol mortality rate was $13.9 / 100,000$ compared to the UK 
Table 3 Cause of death by Socioeconomic Status: SMI compared to Glasgow and Scottish Population Bold if $p<0.05$

\begin{tabular}{|c|c|c|c|c|c|c|}
\hline & \multirow{2}{*}{$\begin{array}{l}\text { Cause of } \\
\text { Death n, (\%) }\end{array}$} & \multicolumn{5}{|l|}{ SIMD Category } \\
\hline & & Most Affluent & & & & Most deprived \\
\hline \multirow[t]{4}{*}{ Accidental } & SMI vs. Glasgow & 0 (0) vs. 9 (3.5) & 0 (0) vs. 21 (4.7) & 1 (2.9) vs. 23 (3.1) & (7.8) vs. 59 (4.6) & 5 (4.7) vs. 88 (5.4) \\
\hline & & $p=0.535$ & $p=0.40$ & $p=0.94$ & $p=0.265$ & $p=0.02$ \\
\hline & SMI vs. Scotland & 0 (0) vs. $273(4.7)$ & 0 (0) vs. 6491 (6.0) & 1 (2.9) vs. 601 (5.8) & 5 (7.8) vs. $618(4.9)$ & 5 (4.7) vs. 899 (5.2) \\
\hline & & $p=0.45$ & $p=0.345$ & $p=0.49$ & $p=0.31$ & $p=0.84$ \\
\hline \multirow[t]{4}{*}{ Alcohol } & SMI vs. Glasgow & 1 (9.1) vs. 18 (7.0) & 0 (0) vs. 38 (8.4) & 1 (2.9) vs. 78 (10.7) & 10 (15.6) vs. 152 (11.8) & 8 (2.8) vs. 746 (13.9) \\
\hline & SMI vs. Scotland & $p=0.693$ & $p=0.26$ & $p=0.178$ & $p=0.425$ & $p=0.003$ \\
\hline & & 1 (9.1) vs. 336 (5.8) & 0 (0) vs. $530(6.4)$ & 1 (2.9) vs. $864(8.4)$ & 10 (15.6) vs. 1275 (10.1) & 8 (2.8) vs. 2314 (13.3) \\
\hline & & $p=0.64$ & $p=0.326$ & $p=0.282$ & $p=0.196$ & $p=0.004$ \\
\hline \multirow[t]{4}{*}{ Cancer } & SMI vs. Glasgow & $0(0)$ vs. 109 (42.4) & 1 (6.7) vs. 163 (36.2) & 1 (32.4) vs. 236 (32.2) & 8 (12.5) vs. 357 (27.8) & $13(12.3)$ vs. $1346(25.1)$ \\
\hline & SMI vs. Scotland & $p=0.03$ & $p=0.067$ & $p=0.992$ & $p=0.0312$ & $p=0.013$ \\
\hline & & $0(0)$ vs. $2726(47.0)$ & 1 (6.7) vs. 3287 (39.9) & 11 (32.4) vs. 3606 (34.9) & 8 (12.5) vs. 3942 (31.2) & 1 (12.3) vs. 4568 (26.3) \\
\hline & & $p=0.025$ & $p=0.050$ & $p=0.829$ & $p=0.011$ & $p=0.008$ \\
\hline \multirow[t]{4}{*}{ Cardiovascular } & SMI vs. Glasgow & 2 (18.2) vs. 33 (12.8) & 1 (6.7) vs. 47 (10.4) & 2 (5.9) vs. 109 (14.9) & 8 (12.5) vs. 171 (13.1) & 21 (19.8) vs. 709 (13.2) \\
\hline & & $p=0.44$ & $p=0.66$ & $p=0.191$ & $p=0.872$ & $p=0.09$ \\
\hline & SMI vs. Scotland & 2 (18.2) vs. 734 (12.7) & 1 (6.7) vs. 1048 (12.7) & 2 (5.9) vs. 1463 (14.2) & 8 (12.5) vs. 1802 (19.3) & 21(19.8) vs.2418 (13.9) \\
\hline & & $p=0.608$ & $p=0.525$ & $p=0.213$ & $p=0.727$ & $p=0.138$ \\
\hline \multirow[t]{4}{*}{ Cerebrovascular } & SMI vs. Glasgow & 1 (9.1) vs. $13(5.1)$ & 2 (13.3) vs. 20 (4.4) & 1 (2.9) vs. 27 (3.7) & 0 (0) vs. 3.4 (44) & 4 (3.8) vs. 200 (3.7) \\
\hline & & $p=0.58$ & $p=0.14$ & $p=0.826$ & $p=0.139$ & $p=0.979$ \\
\hline & SMI vs. Scotland & 1 (9.1) vs. 253 (4.4) & 2 (13.3) vs. 378 (4.6) & 1 (2.9) vs. 390 (3.8) & 0 (0) vs. 478 (3.8) & 4 (3.8) vs. $687(4.0)$ \\
\hline & & $p=0.455$ & $p=0.138$ & $p=0.806$ & $p=0.120$ & $p=0.929$ \\
\hline \multirow{4}{*}{$\begin{array}{l}\text { Mental \& behavioural } \\
\text { disorder due to drugs }\end{array}$} & SMI vs. Glasgow & 0 (0) vs. 4 (1.6) & $2(13.3)$ vs. $12(2.7)$ & $2(5.9)$ vs. 23 (3.1) & 1 (1.6) vs. $58(4.5)$ & 13 (12.3) vs. 315 (5.9) \\
\hline & & $p=0.68$ & $p=0.028$ & $p=0.40$ & $p=0.275$ & $\mathrm{p}<0.001$ \\
\hline & SMI vs. Scotland & 0 (0) vs. $72(1.2)$ & 2 (13.3) vs. 1.7 (138) & 2 (5.9) vs. 238 (2.3) & 1 (1.6) vs. 422 (3.3) & 13 (12.3) vs. $886(5.1)$ \\
\hline & & $p=0.716$ & $p=0.001$ & $p=0.183$ & $p=0.44$ & $p=0.002$ \\
\hline \multirow[t]{4}{*}{ Other } & SMI vs. Glasgow & 1 (9.1) vs. 4.5 (17.5) & 5 (33.3) vs. 91 (20.2) & 8 (23.5) vs. 133 (18.2) & 16 (25.0) vs. 258 (20.1) & 23 (21.2) vs. 965 (18.0) \\
\hline & & $p=0.52$ & $p=0.34$ & $p=0.521$ & $p=0.44$ & $p=0.418$ \\
\hline & SMI vs. Scotland & 1 (9.1) vs. 1043 (18.0) & 5 (33.3) vs. 1447 (17.6) & 8 (23.5) vs. 1899 (18.4) & 16 (25.0) vs. 2381 (1838) & 23 (21.2) vs. 3099 (17.8) \\
\hline & & $p=0.525$ & $p=0.207$ & $p=0.528$ & $p=0.310$ & $p=0.393$ \\
\hline \multirow[t]{4}{*}{ Respiratory } & SMI vs. Glasgow & 0 (0) vs. 11 (4.3) & 2 (13.3) vs. 25 (5.6) & 3 (8.8) vs. 45 (6.1) & 8 (12.5) vs. 98 (7.6) & 11 (10.4) vs. 427 (8.0) \\
\hline & & $p=0.49$ & $p=0.257$ & $p=0.287$ & $p=0.199$ & $p=0.405$ \\
\hline & SMI vs. Scotland & 0 (0) vs. $217(3.7)$ & 2 (13.3) vs. 406 (4.9) & 3 (8.8) vs. 621 (6.0) & 8 (12.5) vs. 888 (7.0) & 11 (10.4) vs. 1319 (7.6) \\
\hline & & $p=0.527$ & $p=0.169$ & $p=0.522$ & $p=0.121$ & $p=0.322$ \\
\hline
\end{tabular}


Table 3 Cause of death by Socioeconomic Status: SMI compared to Glasgow and Scottish Population Bold if $p<0.05$ (Continued)

\begin{tabular}{|c|c|c|c|c|c|c|}
\hline \multirow[t]{4}{*}{ Suicide } & SMI vs. Glasgow & $6(54.6)$ vs. $15(5.8)$ & 2 (13.3) vs 33 (7.3) & 5 (14.7) vs. 58 (7.9) & 8 (12.5) vs. 82 (6.9) & $13(12.3)$ vs. $373(6.9)$ \\
\hline & & $\mathrm{p}<0.001$ & $p=0.433$ & $p=0.208$ & $p=0.08$ & $p=0.054$ \\
\hline & SMI vs. Scotland & $6(54.6)$ vs. 320 (5.5) & 2 (13.3) vs. 519 (16.3) & 5 (14.7) vs. 656 (6.3) & 8 (12.5) vs. 837 (6.6) & 13 (12.3) vs. 1201 (6.9) \\
\hline & & $\mathrm{p}<0.001$ & $p=0.308$ & $p=0.07$ & $p=0.086$ & $p=0.05$ \\
\hline \multirow[t]{2}{*}{ All Cause of death } & SMI vs. Glasgow & 11 vs. 257 & 15 vs. 450 & 34 vs. 732 & 64 vs. 1286 & 106 vs. 5369 \\
\hline & SMI vs. Scotland & 11 vs. 5947 & 15 vs. 8244 & 34 vs. 10388 & 64 vs. 12643 & 106 vs. 17391 \\
\hline
\end{tabular}


average of $8.3 / 100,000$. [36] Our finding of a trend towards significantly higher proportions of drug related deaths and "other" causes of death (which included a wide range of causes) within the SMI cohort may also explain this finding. Given that only the primary cause of death was obtained from the GRO, rates of alcohol as a secondary cause of death within our cohort are unknown and may also explain our lower rates of death due to alcohol.

We also found that the proportion of cardiovascular disease deaths in those with SMI was only marginally higher compared to Glasgow and Scotland. This is in keeping with other studies which have found similar rates of cardiovascular deaths in patients with SMI compared to their local population [29].

\section{The role of deprivation}

We found that, as with the local Glasgow and wider Scottish populations, rate of death in those with SMI increased as deprivation increased. The magnitude of the elevation in mortality associated with deprivation was similar; however, when suicide was excluded as a cause of death, the magnitude of increase in mortality associated with deprivation was greatest for the SMI cohort. This association between deprivation and mortality in those with SMI appear similar to that reported in the general population. Of note, was our finding of a significantly higher proportion of suicide in those with SMI in both the least and most deprived quintiles. While a negative correlation between suicide and socioeconomic status has been found in Australia [37] and the US [38], our finding of a more complex relationship has been identified by others in the UK [39,40]. In particular, Osborn and colleagues found that although suicide rates were increased across all age groups of individuals with SMI, those who were least socially deprived were particularly at risk [41].

Despite the negative impact of deprivation on health outcomes (for example, those living in the most deprived areas are more likely to have unplanned admissions to hospital than those living in the most affluent areas) [42] as well as the premature onset of multimorbidity [42], studies investigating the relationship between socioeconomic status and mortality in individuals with SMI are limited. While there are studies looking at the impact of socioeconomic status on parasuicide [43], suicide [40,44] and cause of death in major depressive disorder [45,46], generalised anxiety disorder [47] and alcohol misuse [48], we found only one study which specifically focused on the impact of socioeconomic status on mortality in bipolar disorder [49] and no studies which specifically focused on the impact of socioeconomic status on mortality in schizophrenia. The study which explored the impact of socioeconomic factors on cause and rate of death in affective disorders was limited due its small sample size of only 30 deaths.

\section{The "Scottish" and the "Glasgow" effects}

Although life expectancy and health behaviours have improved in Glasgow over the past 50 years, the rates of improvement have differed depending on the individuals' socioeconomic status. As Scotland's ranking in terms of European mortality rates have worsened over time, so too has the gap in life expectancy between the most affluent and most deprived areas within Scotland [50,51]. This health inequality associated with socioeconomic status has been mirrored by an inequality in life expectancy associated with SMI [10-14].

Although the impact of deprivation on health and mortality is marked, the differences in life expectancy in Scotland compared to the rest of Europe, and in Glasgow compared to the rest of Scotland, cannot be fully explained by deprivation alone. These gaps in mortality which cannot be explained by deprivation have been termed the "Scottish" and "Glasgow Effects" [52,53]. This "Glasgow Effect" was reflected in our study, where mortality rates for those with SMI were even higher than both the Scottish and Glasgow averages. The differences in mortality between those with SMI and those without also appeared largest for those living in the most deprived quintiles.

Our study of all-cause mortality in those with SMI in Glasgow has identified a trend towards increasing mortality associated with worsening deprivation, but more work is required to investigate this relationship further.

\section{Strengths \& limitations}

Our findings of a gradient in level of deprivation and magnitude of increase in mortality in those with SMI are novel in that we were able to describe the rate and cause of death of individuals with SMI in detail and compare them to both the local Glasgow and wider Scottish populations. To our knowledge, this is the first study to investigate the impact of deprivation on rate and cause of death of those with schizophrenia and bipolar disorder and as such may help inform the development of population-based strategies to improve the life expectancy of individuals with SMI. Additional strengths of this study include the comprehensive nature of the PsyCIS database, which is representative of a large clinical population accessing mental health services in a defined urban area. Regular checks of data accuracy are carried out by the senior medical practitioners involved in case management, thereby maintaining the reliability of diagnoses, clinical and sociodemographic data.

Limitations of this work include the relatively small number of deaths which occurred during our limited study timeframe. Furthermore, exclusion of a small number of 
patients with psychosis who are managed exclusively in primary care also occurred. As PsyCIS is a secondary care based database, inclusion of all people with psychosis in the geographical area would require linkage of the database to primary care records, which is not currently possible. Although some patients with psychosis live independently in the community without input from secondary services, further study is required to ascertain the numbers of such patients in Glasgow. PsyCIS also excludes individuals who are under 16, over 65 years old and who are not managed by general adult community services, such as those whose psychotic illness is managed exclusively in addictions psychiatry, old age psychiatry, or learning disability services. These numbers are likely to be relatively small because the majority of patients of working age with psychotic disorder are managed by adult general psychiatric services. SIMD is a relative measure of deprivation and given the impact of socioeconomic drift in the PsyCIS cohort, wider Glasgow and Scottish population during our five year timeframe, its use has a number of limitations. A further limitation was that of the impact of age on rates and causes of death- although adjustment for age profile of the populations were made, full standardisation was not possible due to small sample sizes.

\section{Conclusion}

In our cohort of patients with SMI the rate and cause of death differed from that of the local Glasgow and wider Scottish populations. There appeared to be a graded effect of deprivation on mortality, which was largest in impact for those with SMI when suicide was excluded as a cause of death. This pattern of rising mortality across deprivation categories may represent evidence of inequalities in health outcomes for the most deprived individuals with SMI. More work is required to investigate this relationship further, in order to inform new approaches to health care organisation, health promotion and screening in those with SMI living in the most deprived communities.

\section{Abbreviations}

GRO: General register office; ICD10: International classification of disease; PsyCIS: Glasgow psychosis clinical information system; SIMD: Scottish index of multiple deprivation; SMI: Severe mental illness; SMR: Standardised mortality rates.

\section{Competing interests}

'The authors declare that they have no competing interests.

\section{Authors' contributions}

$J L M$ and JP had the original idea for the article. JP was involved in data extraction. JP, JLM and GMCL were involved in data analysis. All authors read and approved the final draft.

\section{Authors' information}

Julie Langan Martin is a Clinical Lecturer at the University of Glasgow and an Honorary Specialist Registrar at NHSGG\&C.

Gary McLean is a medical statistician at the University of Glasgow.

John Park is the Lead Research Nurse in the PsyCIS Team at Stobhill Hospital.
Daniel J Martin is a Clinical Research Fellow at the University of Glasgow and an Honorary Specialist Registrar at NHSGG\&C.

Moira Connolly is a Consultant Psychiatrist at NHSGG\&C having previously been the Principal Medical Officer in Mental Health for the Scottish

Government.

Stewart W Mercer is Professor of Primary Care at the University of Glasgow. Daniel J Smith is Reader in Psychiatry at the University of Glasgow and an Honorary Consultant Psychiatrist at NHSGG\&C.

\section{Acknowledgements}

The authors would like to acknowledge Frank Dixon, Statistician, National Records of Scotland, (formerly General Register Office for Scotland) for his help in obtaining GRO data.

\section{Author details}

${ }^{1}$ Institute of Health and Wellbeing, University of Glasgow, Gartnavel Royal Hospital, 1055 Great Western Road, Glasgow G12 0XH, UK. ' Lead Research Nurse PsyCIS Team, Stobhill Hospital, 300 Balgrayhill Road, Glasgow G21 3UR, UK. ${ }^{3}$ Gartnavel Royal Hospital, 1055 Great Western Road, Glasgow G12 0XH, UK. ${ }^{4}$ Institute of Health and Wellbeing, University of Glasgow, General Practice \& Primary Care, 1 Horselethill Road, Glasgow G12 9LX, UK.

Received: 7 February 2014 Accepted: 4 September 2014

Published online: 12 September 2014

\section{References}

1. Strickland S, Shetty P, Maclntyre S: Social inequalities and health in the contemporary world: comparative overview. In Human biology and social inequality (39th symposium volume of the Society for the Study of Human Biology). Cambridge: Cambridge University Press; 1998:20-35.

2. Stirbu I, Kunst A, Mielck A, Mackenbach J: Inequalities in utilisation of general practitioner and specialist services in 9 European countries. BMC Health Serv Res 2011, 11:288.

3. Van Doorslaer E, Masseria C, Koolman X: Inequalities in access to medical care by income in developed countries. CMAJ 2006, 174:177-183.

4. Whyte B, Ajetunmobi T, Glasgow Centre for Population Health (GCPH): Still the Sick Man of Europe? Scottish Mortality in a European Context 1950 2010 An analysis of comparative mortality trends. 2012, http://www.gcph. co.uk/assets/0000/3606/Scottish_Mortality_in_a_European_Context_2012_ v11_FINAL_bw.pdf.

5. Chief Medical Officer: Health in Scotland 2004. Edinburgh: Scottish Executive; 2005.

6. Department of Health: Choosing health; making healthy choices easier. London: The Stationery Office; 2004.

7. ScotPHO Public Health Information for Scotland: http://www.scotpho.org.uk/.

8. Crump C, Sundquist K, Winkleby MA, Sundquist J: Comorbidities and mortality in persons with schizophrenia: a Swedish national cohort study. Am J Psychiatry 2013, 170:324-333.

9. Hoang U, Stewart R, Goldacre MJ: Mortality after hospital discharge for people with schizophrenia or bipolar disorder: retrospective study. BMJ 2011, 343:d5422.

10. Laursen TM, Munk-Olsen T, Gasses C: Chronic somatic comorbidity and excess mortality due to natural causes in persons with schizophrenia or bipolar affective disorder. PLOS ONE 2011, 6:e24597.

11. Wahlbeck K, Westman J, Nordentoft M, Gissler M, Munk LT: Outcomes of Nordic mental health systems: life expectancy of patients with mental disorders. Br J Psychiatry 2011, 199(6):453-458.

12. Chang C-K, Hayes RD, Perera G, Broadbent MTM, Fernandes AC, Lee WE, Hotopf M, Stewart R: Life Expectancy at Birth for People with Serious Mental IIIness and Other Major Disorders from a Secondary Mental Health Care Case Register in London. PLOS ONE 2011, 6(5):e19590. doi:10.1371/journal.pone.0019590.

13. Morden NE, Lai Z, Goodrich DE, Mackenzie T, McCarthy JF, Austin K, Welsh DE, Bartels S, Kilbourne AM: Eight-year trends of cardiometabolic morbidity and mortality in patients with schizophrenia. Gen Hosp Psychiatry 2012, 34:368-379.

14. Lawrence D, Hancock K, Kisley S: The gap in life expectancy from preventable physical illness in psychiatric patients in Western Australia: retrospective analysis of population based registers. BMJ 2013, 346:f2539. doi:10.1136/bmj.f2539. 
15. Smith DJ, Langan J, McLean G, Guthrie B, Mercer SW: Schizophrenia is associated with excess multiple physical-health comorbidities but low levels of recorded cardiovascular disease in primary care: cross-sectional study. BMJ Open 2013, 3:e002808. doi:10.1136/ bmjopen-2013-002808.

16. Smith DJ, Martin DJ, McLean G, Langan Martin J, Guthrie B, Mercer SW: Multimorbidity in bipolar disorder and under treatment of cardiovascular disease: cross sectional study. BMC Medicine 2013, 11:263-274.

17. Lambert TJ, Newcomer JW: Are the cardiometabolic complications of schizophrenia still neglected? Barriers to care. Med J Aust 2009, 190:S39-S42.

18. DE Hert M, Correll CU, Bobes J, Cetkovich-Bakmas M, Cohen D, Asai I, Detraux J, Gautam S, Möller HJ, Ndetei DM, Newcomer JW, Uwakwe R, Leucht S: Physical illness in patients with severe mental disorders. Prevalence, impact of medications and disparities in health care. World Psychiatry 2011, 10(1):52-77.

19. Frayne SM, Halanych JH, Miller DR, Wang F, Lin H, Pogach L, Sharkansky EJ, Keane TM, Skinner KM, Rosen CS, Berlowitz DR: Disparities in diabetes care: impact of mental illness. Arch Intern Med 2005, 165(22):2631-2638.

20. Weiss AP, Henderson DC, Weilburg JB, Goff DC, Meigs JB, Cagliero E, Grant RW: Treatment of cardiac risk factors among patients with schizophrenia and diabetes. Psychiatr Serv 2006, 57(8):1145-1152.

21. Laursen TM, Munk-Olsen T, Agerbo E, Gasse C, Mortensen PB: Somatic hospital contacts, invasive cardiac procedures, and mortality from heart disease in patients with severe mental disorder. Arch Gen Psychiatry 2009, 66(7):713-720

22. Aro S, Aro H, Keskimäki I: Socio-economic mobility among patients with schizophrenia or major affective disorder. A 17-year retrospective follow-up. Br J Psychiatry 1995, 166(6):759-767.

23. Park J, McAlaney C, Connolly M: Improving patient care and clinical governance through utilisation of a clinical information system. Clin Govern 2008, 13(4):254-259.

24. eDRIS Produucts \& Services ISD Scotland. Accessible at http://www. isdscotland.org/Products-and-Services/eDRIS/.

25. Sources of Information for Coding the Causes of Death GRO for Scotland. Available at: http://www.gro-scotland.gov.uk/files2/stats/ ve-reftables-2011/ve2011-t5-1.pdf.

26. Definition of Statistics: Probable Suicides: Deaths which are the Result of Intentional Self-harm or Events of Undetermined Intent. Available at http://www.gro-scotland.gov.uk/statistics/theme/vital-events/deaths/ suicides/definition-of-stats/index.html.

27. Overview of the Scottish Index of Multiple Deprivation. Available at: http://simd.scotland.gov.uk/publication-2012/introduction-to-simd-2012/ overview-of-the-simd/what-is-the-simd/.

28. Baxter DN: The mortality experience of individuals on the Salford Psychiatric Case Register. All-cause mortality. Br J Psychiatry 1996, 168:772-779.

29. Colton CW, Manderscheid RW: Congruencies in increased mortality rates, years of potential life lost, and causes of death among public mental health clients in eight states. Prev Chronic Dis 2006, 3:A42.

30. Osborn DP, Levy G, Nazareth I, Petersen I, Islam A, King MB: Relative risk of cardiovascular and cancer mortality in people with severe mental illness from the United Kingdom's General Practice Research Database. Arch Gen Psychiatry 2007, 64:242-249.

31. Tran E, Rouillon F, Loze JY, Casadebaig F, Philippe A, Vitry F, Limosin F: Cancer mortality in patients with schizophrenia: an 11-year prospective cohort study. Cancer 2009, 1(15):3555-3562.

32. Oksbjerg Dalton S, Munk Laursen T, Mellemkjaer L, Johansen C, Mortensen PB: Schizophrenia and the risk for breast cancer. Schizophr Res 2003, 62:89-92.

33. Catts VS, Catts SV, O'Toole BI, Frost ADJ: Cancer incidence in patients with schizophrenia and their first-degree relatives - a meta-analysis. Acta Psychiatr Scand 2008, 117:323-336.

34. Regier DA, Farmer ME, Rae DS, Locke BZ, Keith SJ, Judd LL, Goodwin FK: Comorbidity of mental disorders with alcohol and other drug abuse. Results from the Epidemiologic Catchment Area (ECA) Study. JAMA 1990, 264(19):2511-2518.

35. Rosenberg SD, Drake RE, Wolford Gl, Mueser KT, Oxman TE, Vidaver RM, Carrieri KL, Luckoor R: Dartmouth assessment of lifestyle instrument (DALI): a substance use disorder screen for people with severe mental illness. Am J Psychiatry 1998, 155(2):232-238.

36. Alcohol related Mortality Institute of Alcohol Studies. http://www.ias.org.uk Alcohol-knowledge-centre/Health-impacts/Factsheets/Alcohol-relatedmortality-rates.aspx.
37. Taylor R, Morrell S, Slaytor E, Ford P: Suicide in Urban New South Wales, Australia 1985-1994. Socio-economic and Migrant Interactions. Soc Sci Med 1998, 47:1677-1686.

38. Kposowa AJ: Unemployment and suicide: a cohort analysis of social factor predicting suicide in the US: National Longitudinal Mortality Study. Psychol Med 1999, 31:127-138.

39. Hawton K, Harris L, Simkin S, Bale E, Bond A: Social class and suicidal behaviour: the associations between social class and the characteristics of deliberate self-harm patients and the treatment they are offered. Soc Psychiatry Psychiatr Epidemiol 2001, 36:437-443.

40. Osborn D, Levy G, Nazareth I, King M: Suicide and severe mental illnesses. Cohort study within the UK general practice research database. Schizophr Res 2008, 99(1-3):134-138. Epub 2007 Dec 26.

41. Payne RA, Abel GA, Guthrie B, Mercer SW: The effect of physical multimorbidity, mental health conditions and socioeconomic deprivation on unplanned admissions to hospital: a retrospective cohort study. CMAJ 2013, 185(5):E221-E228. doi:10.1503 /cmaj.121349.

42. Barnett K, Mercer SW, Norbury M, Watt G, Wyke S, Guthrie B: Epidemiology of multimorbidity and implications for health care, research, and medical education: a cross-sectional study. Lancet 2012, 380:37-43.

43. Gunnell DJ, Peters TJ, Kammerling RM, Brooks J: Relation between parasuicide, suicide, psychiatric admissions, and socioeconomic deprivation. BMJ 1995, 311(6999):226-230

44. Congdon P: Assessing the Impact of Socioeconomic variables on small area variations in suicide outcomes in England. Int J Environ Res Public Health 2013, 10(1):158-177.

45. Surtees PG, Wainwright NW, Luben RN, Wareham NJ, Bingham SA, Khaw KT: Depression and ischemic heart disease mortality: evidence from the EPIC-Norfolk United Kingdom prospective cohort study. Am J Psychiatry 2008, 165(4):515-523. doi:10.1176/appi.ajp.2007.07061018. Epub 2008 Feb 1.

46. Scafato E, Galluzzo L, Ghirini S, Gandin C, Rossi A, Solfrizzi V, Panza F, Di Carlo A, Maggi S, Farchi G, ILSA Working Group: Changes in severity of depressive symptoms and mortality: the Italian Longitudinal Study on Aging. Psychol Med 2012, 42(12):2619-2629. doi:10.1017/S0033291 712000645. Epub 2012 Apr 11.

47. Phillips AC, Batty GD, Gale CR, Deary IJ, Osborn D, Maclntyre K, Carroll D: Generalized anxiety disorder, major depressive disorder, and their comorbidity as predictors of all-cause and cardiovascular mortality: the Vietnam experience study. Psychosom Med 2009, 71(4):395-403. doi:10.1097/PSY.0b013e31819e6706. Epub 2009 Mar 25

48. Singh GK, Hoyert DL: Social epidemiology of chronic liver disease and cirrhosis mortality in the United States, 1935-1997: trends and differentials by ethnicity, socioeconomic status, and alcohol consumption. Hum Biol 2000, 72(5):801-820.

49. Schneider $B$, Müller MJ, Philipp M: Mortality in affective disorders. J Affect Disord 2001, 65(3):263-274.

50. Inequalities in mortality in Scotland 1981-2001. Available at http://www. sphsu.mrc.ac.uk

51. Life Expectancy in Scottish Areas GRO for Scotland. Available at http:// www.gro-scotland.gov.uk/statistics/theme/life-expectancy/scottish-areas/ index.html.

52. McCartney G, Shipley M, Hart C, Davey Smith G, Kivimaki M, Walsh D, Watt G, Batty GD: Why do males in Scotland die younger than those in England? Evidence from three prospective cohort studies. PLOS ONE 2012, 7:7-18. ISSN 1932-6203.

53. Walsh D, Bendel N, Jones N, Hanlon P: Investigating a Glasgow Effect. Why do equally deprived UK cities experience difference health outcomes? In Glasgow Centre for Population Health; http://www.gcph.co.uk/assets/0000/0087/Investigating_a_Glasgow_Effect_ for_web.pdf

doi:10.1186/s12888-014-0261-4

Cite this article as: Martin et al:: Impact of socioeconomic deprivation on rate and cause of death in severe mental illness. BMC Psychiatry $201414: 261$ 